\title{
ОСОБЕННОСТИ КАДРОВОГО ОБЕСПЕЧЕНИЯ СТРОИТЕЛЬНОЙ СФЕРЫ В УСЛОВИЯХ ФОРМИРОВАНИЯ ЦИФРОВОЙ ЭКОНОМИКИ
}

\section{FEATURES OF STAFF SUPPLY IN THE CONSTRUCTION SPHERE IN THE CONDITIONS OF FORMATION OF THE DIGITAL ECONOMY}

\section{S. Shirshikov V. Vinogradova}

Summary. In the digital economy, a transformation of all spheres of economic activity is taking place, which necessitates the use of qualitatively new approaches to the staffing of organizations, including the investment and construction sector. The article examines the features of staffing in the construction sector in the context of the formation of the digital economy, describes the process of replacing traditional professions in construction with new ones related to digital technologies. The authors admit that the personnel training system should develop in students the competence of working with digital technologies, including in a remote work format, which is becoming more widespread in the construction industry.

Keywords: staffing, construction industry, competencies, digital economy.

$\Phi$ ормирование цифровой экономики является ключевым фактором, оказывающим влияние на развитие всех видов экономической деятельности, в том числе и на инвестиционно-строительную. На долю строительства в 2019 г. приходилось 5,6\% ВВП России [1]. По состоянию на 2020 г. в России более 6,4 млн. человек занято в строительстве, что составляет 9\% об общей численности занятых в стране [1].

Одним из основоположников понятия цифровой экономики Д. Тэпскоттом было дано следующее определение: «Цифровая экономика - всеобъемлющий и революционный процесс, основанный на конвергенции достижений в области человеческих коммуникаций, вычислительной техники и формирования контента, для создания интерактивных мультимедиаи информационных магистралей, заставляющий переосмыслить традиционные определения экономики, создания материальных ценностей, деловых организаций и других институциональных структур» [2].

\author{
Ширшиков Сергей Павлович \\ К.э.н., дочент, Санкт-Петербургский \\ государственный архитектурно-строительный \\ университет \\ shirshikov.spb@gmail.com \\ Виноградова Виктория Витальевна \\ К.э.н., Санкт-Петербургский государственный \\ архитектурно-строительный университет \\ vittoria.vinogradova@gmail.com
}

Аннотация. В условиях цифровой экономики происходит трансформация всех сфер экономической деятельности, что обуславливает потребность в применении качественно новых подходов к кадровому обеспечению организаций, в том числе инвестиционно-строительной сферы. В статье рассмотрены особенности кадрового обеспечения строительной сферы в условиях формирования цифровой экономики, дана характеристика процессу замещения традиционных профессий в строительстве новыми, связанными с цифровыми технологиями. Авторами признается, что система подготовки кадров должна развивать у обучающихся компетенции работы с цифровыми технологиями, в том числе в удаленном формате работы, получающим всё большее распространение в строительной сфере.

Ключевые слова: кадровое обеспечение, строительная сфера, компетенции, цифровая экономика.

В России переход к цифровой экономике регулируется национальной программой «Цифровая экономика Российской Федерации [3], в рамках которой принят федеральный проект «Кадры для цифровой экономики». Среди основных задач данного проекта выделяют развитие у населения компетенций работы с цифровыми технологиями, способствующих повышению их востребованности на рынке труда, для чего необходимо повышать доступность программ дополнительного образования, связанных с современными технологиями [4]. В целом признается, что для развития цифровой грамотности и сетевого сотрудничества информационные технологии должны внедряться в учебную деятельность всех уровней подготовки [5].

Цифровая трансформация обуславливает важность применения современных методов производства готовой продукции, выполнения работ и оказания услуг, и строительная сфера не является исключением. В инвестиционно-строительной сфере всё большее рас- 
пространение получают такие технологии как Building Information Modelling (BIM), дополненная и виртуальная реальность, big data и предиктивная аналитика, 3D-печать, Интернет вещей [6]. По мнению П. Акимова, приобретение компетенций для работы с цифровыми технологиями в строительстве возможно в рамках программ повышения квалификации [7]. Признается, что современная система образования должна включать в себя образовательные учреждения всех уровней подготовки, центры переподготовки и повышения квалификации и ресурсные учебные центры по отраслевым направлениям [8].

Кроме того, НОСТРОЙ предлагает решать проблему дефицита квалифицированных кадров в строительстве за счет создания единой информационной платформы на основе объединения Национального реестра специалистов и Единого реестра членов СРО с указанием опыта работы, образования и квалификации специалиста, что позволит организациям эффективно находить сотрудников, отвечающих требованиям работы в цифровой экономике [9].

Тем не менее при рассмотрении особенностей кадрового обеспечения строительства нельзя не указать на важность разделения задача между сотрудниками организаций на такие категории как «Умение», «Правило» и «Знание», предложенную Й. Расмуссеном [10]. Для сотрудников категории «Умение» характерны выполнение типовых задач, преимущественного физический труд, не требующий специализированной подготовки; компетенции для категории «Правило» включают в себя выполнение работ по определенным правилам и инструкциям на основе пройденной прикладной подготовки, в то время как сотрудники с задачами группы «Знание» должны обладать навыками к аналитической работе в условиях неопределенности, автономности принятия решений, что требует специализированного образования и всеобъемлющего понимания ситуации в сфере деятельности организации. По оценкам экспертов BCG, в России к 2025 г. около 10 млн. человек категорий «Умение» и «Правило» станут не востребованы, при этом нехватка специалистов категории «Знание» составит 9,2 млн. человек [10], что требует адаптации населения к требованиям работы в цифровой экономике.

Для строительства уже характерно сокращение потребности в каменщиках, плотниках, техниках-смотрителях, охранниках, а также узконаправленных специалистах по росписи, лепнине, печному делу. Их компетенции могут быть применены в элитном, индивидуальном строительстве и реконструкции, однако всё чаще на смену им приходят автоматизированные системы контроля и выполнения работ. В перспективе 10-15 лет могут исчезнуть профессии техника по стан- дартизации, кровельщика, изолировщика, строителя-монтажника, штукатура, бетонщика, настильщика полов и плиточника, сварщика, газорезчика, маляра, арматурщика, стекольщика и др. [11].

С другой стороны, всё более востребованными становятся профессии, находящиеся на стыке категорий «Правило» и «Знание», среди которых можно выделить архитектора «энергонулевых» домов, ВІМ-менеджера-проектировщика, специалиста по перестройке/ усилению старых строительных конструкций, проектировщика 3D-печати в строительстве, экоаналитика в строительстве, проектировщика доступной среды, прораба-вотчера, проектировщика инфраструктуры «умного дома», специалиста по модернизации строительных технологий, диспетчера дронов, аналитика Big Data в строительстве, менеджера по инновациям, специалиста по устойчивому строительству [11, 12].

Некоторые профессии, относящиеся в настоящее время к категории «Знание», такие как риелтор, ипотечный брокер, и профессии категории «Правило», среди которых инженер-сметчик и менеджер по показу квартир, постепенно будут заменены цифровыми технологиями BIM, 3D-моделями жилья, сервисами для поиска, покупки, продажи, аренды по принципу «одного окна» [13]. По мнению специалистов ProPersonnel, представители поколения Z (1995-2015 года рождения) предпочитают выбирать жилье и совершать сделки посредством онлайн-сервисов, например с помощью запущенного в 2016 г. в США автоматизированного риелтора REX, комиссия которого на 70\% ниже, чем при работе с риелтором [13].

Пандемия Covid-19 также привела к ускорению перехода строительной сферы на цифровые технологии. По оценкам McKinsey, в 2020 г. строительными организациями активнее, чем ранее, применялись технологии цифрового контроля за ходом строительства, оптимизации графика выполнения работ, причем в удаленном формате работы высококвалифицированных специалистов [14]. Пандемия способствовала использованию 4D и 5D BIM, модульного строительства, датчиков с искусственным интеллектом.

Строительной сфере также присуща высокая мобильность кадров в связи с реализацией проектов на удаленных друг от друга территориях или в разных регионах страны [15]. Одним из способов снижения текучести высококвалифицированных кадров от проекта к проекту является использование цифровых технологий, способствующих удаленному характеру работы специалистов.

В цифровой экономике уже пересматривается понятие офиса, и всё чаще применяется формат удаленной 
работы, который позволяет сократить затраты на аренду помещений [16], однако необходимо учитывать потребность сотрудников в коммуникации, которая не должна стать менее эффективной, чем при традиционном формате работы. Вопросы кадрового обеспечения в строительстве должны рассматриваться с учетом навыков well-being, непосредственно связанных с корпоративной средой. Сочетание различных форматов работы сотрудников должно обеспечивать и эффективность деятельности организации, и работоспособность сотрудников с точки зрения эмоционального и физического здоровья [17].

Также полный переход на удаленные рабочие места в строительстве невозможен в связи со спецификой деятельности, поэтому физический труд необходимо как можно больше автоматизировать как в целях повышения безопасности производства работ, так и снижения затрат на реализацию проектов на долгосрочном горизонте анализа.

Роботизация и цифровизация процессов инвестиционно-строительной сферы признается зарубежными специалистами как неизбежный этап формирования цифровой экономики, который приведет к росту потребности в профессиях, связанных с информационной безопасностью, искусственным интеллектом, удаленным выполнением опасных работ и пр. [18].

Многие традиционные профессии в строительстве в условиях цифровой экономики трансформируются: инженеры-электрики в инженеров «умных» сетей электроснабжения; инженеры-строители, архитекторы и проектировщики в специалистов с навыками работы с ВIM; геодезисты в цифровых картографов, умеющих работать с лазерным сканированием; операторы на производстве в операторов аддитивного произ- водства; специалисты в области техники в инженеров вычислительного материаловедения, инженеров виртуальной метрологии в инженеров цифровых стандартов; инспекторы по контролю качества и охране труда в цифровых строительных и пожарных инспекторов [11].

Следовательно, в условиях цифровой экономики возрастает важность наличия компетенций работы с информационно-коммуникационными технологиями, аналитических способностей, навыков коммуникации и умений прогнозировать ситуацию и принимать решения в условиях риска и неопределенности [19]. В настоящее время сотрудники строительных организаций должны быть способны работать со специализированным программным обеспечением, уметь анализировать большие потоки информации, адаптироваться к изменяющейся среде, приобретая данные навыки посредством непрерывного образования [20].

Таким образом, становление цифровой экономики трансформирует подходы к кадровому обеспечению строительной сферы. Изменение форматов работы сотрудников, появление новых профессий и потребность в постоянном развитии навыков работы с цифровыми технологиями обуславливает новые задачи по поиску специалистов с соответствующими компетенциями и формированию корпоративной среды, которая будет обеспечивать эффективную реализацию инвестиционно-строительных проектов. Ключевой особенностью кадрового обеспечения строительства становится способность всех участников реализации проектов быстро реагировать на технологические изменения, что, в свою очередь, требует наличия системы подготовки кадров, способной отвечать современным требованиям к квалификации специалистов.

\section{ЛИТЕРАТУРА}

1. Строительство в России. 2020: Стат. сб. / Росстат.-M., 2020.- 113 с.

2. Tapscott D. The Digital Economy: Promise and Peril in the Age of Networked Intelligence. New York: McGraw-Hill. 1995.

3. Национальная программа «Цифровая экономика Российской Федерации» (утв. протоколом заседания президиума Совета при Президенте Российской Федерации по стратегическому развитию и национальным проектам от 4 июня 2019 г. № 7). URL: http://government.ru/info/35568/ (дата 0бращения: 10.08.2021).

4. Министерство цифрового развития, связи и массовых коммуникаций Российской Федерации. Кадры для цифровой экономики. URL: https://digital. gov.ru/ru/activity/directions/866/ (дата обращения: 10.08.2021).

5. Виноградова В.В. Проблемы и перспективы современного образования в рамках развития цифровых технологий // Материалы V Международной научно-практической конференции «Педагогические параллели». СПб.: Санкт-Петербургский государственный архитектурно-строительный университет, 2018. С. 114-120.

6. IDC. Digital Transformation: The Future of Connected Construction. 2020. URL: https://constructioncloud.autodesk.com/rs/572-JSV-775/images/Autodesk-IDCDigital\%20Transformation_The-Future-of-Connected-Construction.pdf (дата обращения: 15.08.2021).

7. К Ко и как научит быть строителем? // Строительство. 2021. № 5-6. С. 42-45. URL: http://ancb.ru/files/pdf/pc/0traslevoy_zhurnal_Stroitelstvo_-_2021_ god_06_2021_pc.pdf (дата обращения: 11.08.2021). 
8. Аблязов Т.Х., Щербина Г.Ф. Проблемы кадрового обеспечения строительной сферы и механизмы их решения в условиях формирования цифровой экономики // Материалы VI Международной научно-практической конференции «Педагогические параллели». СПб.: Санкт-Петербургский государственный архитектурно-строительный университет, 2018. С. 3-7.

9. НОСТРОЙ использует широкий спектр инструментов для решения кадрового вопроса в строительстве. 2021. URL: https://www.vedomosti.ru/press_ releases/2021/09/03/nostroi-ispolzuet — shirokii-spektr-instrumentov-dlya-resheniya-kadrovogo-voprosa-v-stroitelstve (дата 0бращения: 16.08.2021).

10. BCG Review. 2017. № 42. URL: https://image-src.bcg.com/Images/BCG_Review_November-2017_tcm27-178366.pdf (дата 0бращения: 10.08.2021).

11. Атлас новых профессий и компетенций в Республике Казахстан. URL: https://www.enbek.kz/atlas/professions?department=9\&endangeredPage=2 (дата обращения: 14.08.2021).

12. Атлас новых профессий. URL: https://atlas100.ru/catalog/stroitelstvo/ (дата обращения: 14.08.2021).

13. Топ-5 строительных профессий, которые могут исчезнуть из-за COVID-19. URL: https://www.domostroydon.ru/statyi/obzory/top-5-stroitelnyh-professiykotorye-mogut-ischeznut-iz-za-covid-19 (дата обращения: 15.08.2021).

14. Phillips Z. McKinsey: COVID-19 will spur construction's tech use. URL: https://www.constructiondive.com/news/mckinsey-covid-19-will-spur-constructionstech-use/578335/ (дата обращения: 14.08.2021).

15. Вишнивецкая А.И., Аблязов Т.Х. Обеспечение информационной безопасности строительных организаций // Материалы Всероссийской научно-практической конференции членов РААСН, профессорско-преподавательского состава, молодых ученых СПбГАСУ и специалистов инвестиционно-строительной сферы «Экономические проблемы в архитектуре, градостроительстве и инвестиционно-строительной деятельности. Современное состояние и вызовы». СПб.: Санкт-Петербургский государственный архитектурно-строительный университет, 2019. С. $72-77$.

16. Фоссен Ф., Зоргнер А. Будущее труда: деструктивные и трансформационные эффекты цифровизации // Форсайт. 2019. Т. 13. № S2. С. 10-18.

17. Чуланова 0.Л. Компетенции персонала в цифровой экономике: операционализация soft skills персонала организации с учетом ортобиотических навыков и навыков well-being // Вестник Евразийской науки. 2019. № 2. URL: https://esj.today/PDF/22ECVN219.pdf (дата обращения: 20.08.2021).

18. NBC. From long lost arts to new eras: we predict the construction jobs of the future. 2018. URL: https://www.thenbs.com/knowledge/future-jobs (дата 06paщения: 20.08.2021).

19. Шмелькова Л.В. Кадры для цифровой экономики: взгляд в будущее // Дополнительное профессиональное образование в стране и мире. 2016. № 8 (30). URL: http://www.dpo-edu.ru/wordpress/wp-content/uploads/Shmelkova_DP0_magazine_8-2016.pdf (дата обращения: 21.08.2021).

20. Белолипецкая А.Е., Поповичева Н.Е., Варламов Н.В. Цифровые компетенции персонала и их влияние на развитие кадрового менеджмента организаций // Среднерусский вестник общественных наук. 2019. Т. 14. № 4. С. 56-70.

( ) Ширшиков Сергей Павлович ( shirshikov.spb@gmail.com ), Виноградова Виктория Витальевна ( vittoria.vinogradova@gmail.com ).

Журнал «Современная наука: актуальные проблемы теории и практики»

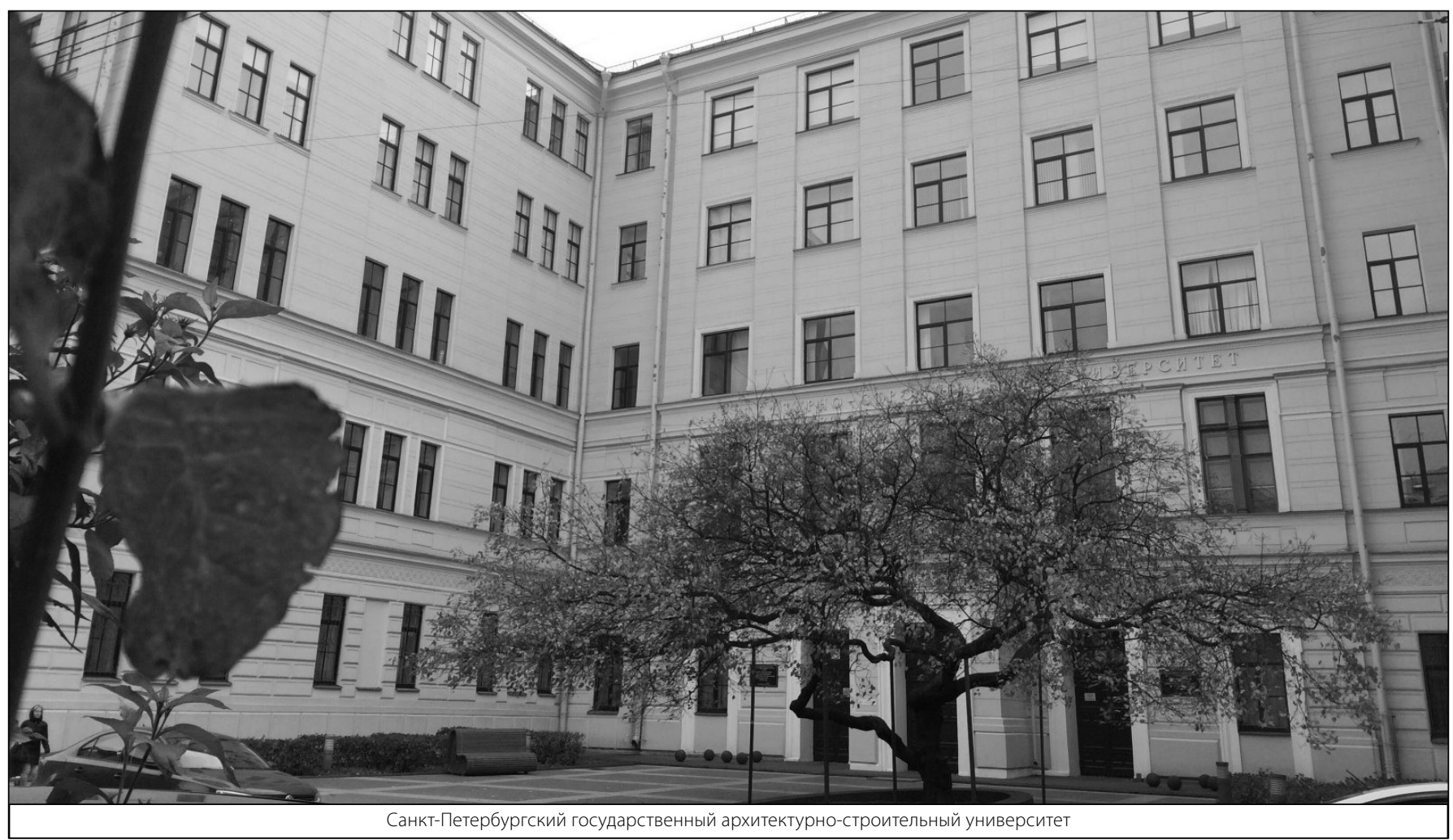

